\title{
Nanosilver: Propriedades, Aplicações e Impactos na Saúde Pública e Meio Ambiente
}

\author{
Nanosilver: Properties, Applications and Impacts on Health and \\ Environment
}

Patricia F. M. Nogueira, lêda Maria M. Paino, Valtencir Zucolotto Grupo de Nanomedicina e Nanotoxicologia, Instituto de Física de São Carlos, Universidade de São Paulo (Gnano/USP), São Carlos, $S P$, Brasil

\section{RESUMO}

A nanotecnologia se desenvolveu rapidamente durante a última década, com aplicações em áreas estratégicas, incluindo saúde, energia, eletrônica, entre outras. Atualmente, a nanotecnologia possui um campo de atuação multidisciplinar, sendo o desenvolvimento e utilização de nanopartículas um dos mais importantes campos de aplicação. A alta demanda comercial das nanopartículas de prata (NPAg) e o aumento dos riscos desses compostos de alcançarem os diferentes ecossistemas e, assim, causarem impacto nesses ambientes e na saúde humana têm provocado amplo debate na comunidade científica. A presente revisão faz um breve levantamento do impacto ambiental das NPAg, como transformação, biodisponibilidade e toxicidade e suas consequências para saúde pública, além de uma descrição sobre a atual legislação internacional.

PALAVRAS-CHAVE: Nanosilver, nanopartículas de prata, nanomedicina, nanotoxicologia

\begin{abstract}
Nanotechnology has developed rapidly in the last decade as a multidisciplinary field, with a myriad of applications in strategic areas including energy, electronics, medicine, biotechnology, among others. In modern days, the high commercial demand of silver nanoparticles (NPAg), in particular, has motivated a broad debate in the scientific community. This review gives a brief survey of the applications, commercialization and possible impacts of NPAg to human health and environment, with focus on their toxicity, transformation, and bioavailability. We also present a description of the current international laws and regulations regarding commercialization of nanomaterials.
\end{abstract}

KEYWORDS: Nanosilver, silver nanoparticles, nanomedicine, nanotoxicology 


\section{Introdução}

As nanopartículas possuem dimensões extremamente pequenas, da ordem de dezenas de nanômetros, apresentam uma grande área superficial e exibem propriedades mecânicas, óticas, magnéticas e químicas distintas de partículas e superfícies macroscópicas. 0 aproveitamento dessas propriedades em aplicações tecnológicas forma a base da nanotecnologia de materiais ${ }^{1}$. No entanto, as mesmas propriedades que tornam os nanomateriais tão atrativos, como pequeno tamanho, forma variada e alta área superficial, podem também ser responsáveis por desequilíbrios ambientais e efeitos nocivos aos organismos vivos e ao homem ${ }^{2,3,4,5}$.

$\mathrm{O}$ avanço da nanotecnologia vem impulsionando o mercado mundial e potencializando o consumo de materiais, produtos e processos voltados para essa área. Tal fato é verificado através do uso de nanoprodutos em diferentes segmentos como alimentício, eletrônico, farmacêutico, biotecnológico, cosmético, médico-hospitalar, agrícola, entre outros ${ }^{6,7}$. Como consequência, uma variedade de nanopartículas está sendo sintetizada, processada e descartada, em proporções cada vez maiores, sem um prévio conhecimento dos seus possíveis efeitos tóxicos ${ }^{8}$. Dentre essas nanopartículas destacam-se as metálicas, incluindo as de prata (NPAg), de ouro (NPAu), de óxidos - principalmente à base de óxidos de ferro e titânio -, nanopartículas poliméricas, semicondutoras ou a base de carbono ${ }^{9}$. 0 amplo desenvolvimento e aplicações de diferentes sistemas nanoparticulados têm provocado uma grande discussão acerca dos riscos potenciais desses compostos à saúde humana e ao ambiente ${ }^{1}$. Apesar dos grandes esforços no estudo da interação de nanopartículas com sistemas biológicos, ainda sabe-se pouco sobre a biodisponibilidade, biodegradabilidade e toxicidade dos nanomateriais nos diferentes sistemas.

Dentre as nanopartículas metálicas em estudo atualmente, as nanopartículas de prata, ou nanosilver, como têm sido denominadas, representam um dos principais sistemas para aplicações em saúde, principalmente devido às suas características biocidas, baixo custo e facilidade de preparação. No entanto, as mesmas características que tornam as NPAg interessantes, também as fazem apresentar um grande potencial de causar riscos à saúde humana ${ }^{10,11}$ e outros seres vivos ${ }^{12,13,14,15,16,17}$, resultando em impacto negativo tanto para o ambiente quanto à saúde pública.

Apesar de a toxicidade da prata já estar bem caracterizada, não existe evidência de que o homem é afetado pelas NPAg contidas em produtos comercializáveis. No entanto, tais produtos podem ser responsáveis pela entrada, tanto das NPAg, quanto de íons de prata, no ambiente, tendo como consequência sua persistência e bioacumulação ${ }^{18,19}$. 0 conhecimento dos riscos que as NPAg podem causar ao homem e ao ecossistema é de fundamental importância, principalmente no que se refere aos ambientes aquáticos, visto o agravamento de problemas mundiais quanto à escassez e disponibilidade de água para os diversos usos múltiplos, e sua relevância para saúde pública.

\section{Nanopartículas de prata - Nanosilver}

Dentre os diversos tipos de nanomateriais com potencial de aplicação em áreas médicas, podemos citar as nanopartículas carreadoras, que incluem os lipossomos, e as nanopartículas lipídicas sólidas, nanoemulsões ${ }^{20}$, as quais podem também ser conjugadas com compostos biológicos, como os quimioterápicos, com atividade no combate ao câncer, e as nanopartículas inorgânicas, como as metálicas, as de óxidos (por exemplo, as de óxido de zinco e de ferro) e as NPAg, entre outras.

Mesmo existindo diversos métodos de síntese de NPAg, o método de redução química da prata, utilizando-se o boro-hidreto de sódio e polivinilpirrolidona (PVP - estabilizante para prevenção da agregação), tem sido o método mais utilizado ${ }^{21}$. De certa forma, a estabilidade das nanopartículas também ocorre através da conjugação com algum tipo de revestimento, e como exemplo podemos citar as NPAg conjugadas com proteínas ${ }^{22}$. Além disso, condições do meio ambiente, como $\mathrm{pH}$, força iônica e a carga elétrica, influenciam na estabilidade delas e, consequentemente no tamanho e nos mecanismos de toxicidade ${ }^{23}$, uma vez que nanopartículas de diferentes tamanhos exercem toxicidades diferentes ${ }^{24}$. Pelo fato de as nanopartículas menores possuírem maior área superficial, podem exibir maior toxicidade e maior atividade microbicida, uma vez que liberam mais íons $\mathrm{Ag}^{+23,24}$.

Como ainda não há padronização internacional quanto à toxicidade das nanopartículas em relação ao tamanho, os estudos de nanotoxicologia ainda são muito controversos na literatura e variam de acordo com o tipo celular estudado (em testes in vitro), o tipo de revestimento da nanopartícula e, principalmente, com o tamanho.

\section{Produtos aplicáveis e em comercialização a base de NPAg}

Recentemente, o número de produtos comercializados contendo algum nanomaterial tem aumentado consideravelmente, sendo as NPAg as mais comercializadas ${ }^{25}$. Devido às suas propriedades físico-químicas e características ótico-eletrônicas, os nanomateriais inorgânicos têm um grande potencial como moléculas terapêuticas no combate ao câncer ${ }^{26}$. Acredita-se que as NPAg, devido ao seu vasto campo de aplicação em biotecnologia e em medicina, sejam as mais populares, em virtude de seu amplo espectro de atividade bactericida, fungicida ${ }^{27,28,29}$, com aplicação no revestimento de catéteres e curativos, entre outros ${ }^{30,31}$. Dados recentes mostram a aplicação de NPAg em aproximadamente $70 \%$ dos produtos na área da saúde e em cosméticos; nos $30 \%$ restantes podemos incluir produtos na área têxtil, alimentos e bebidas, eletrônicos, produtos domésticos e para acondicionamento ${ }^{32}$.

\section{Toxicidade de Nanopartículas de Prata para a saúde humana}

O potencial citotóxico e genotóxico das NPAg tem sido relatado por vários trabalhos na literatura, associado ao dano ao 
DNA, apoptose e necrose, cujo principal mecanismo de ação parece envolver a liberação exacerbada de espécies reativas de oxigênio (do Inglês, Reactive Oxigen Species - ROS) ${ }^{11,33,34,35}$. Como já mencionado, o mecanismo de toxicidade das NPAg ainda não é totalmente esclarecido, mas parece estar relacionado principalmente ao tamanho e às características físico-químicas delas, pois nanopartículas menores têm exibido maior potencial de invasividade celular e, portanto, maior probabilidade de atingirem órgãos como o pulmão, no caso de via de exposição inalatória ${ }^{36}$; dessa forma, o efeito tóxico está relacionado à reatividade, que depende de tais características físico-químicas.

A toxicidade de materiais nanoestruturados, em especial das nanopartículas de prata, tem causado muitas preocupações, pois pode impactar na toxicidade de vários órgãos primários através da distribuição na circulação sistêmica, ocasionando efeitos tóxicos também em outros órgãos, como sistema cardiovascular e sistema nervoso central (SNC) ${ }^{37}$. Um estudo recente indica que as NPAg ultrapassam a barreira hemato-encefálica, atingindo o SNC, cujo mecanismo de ação poderia ser a geração de ROS em excesso ${ }^{38}$. A figura 1 mostra a mudança de morfologia de células tumorais de cérebro humano da linhagem U251, após incubação com as NPAg.

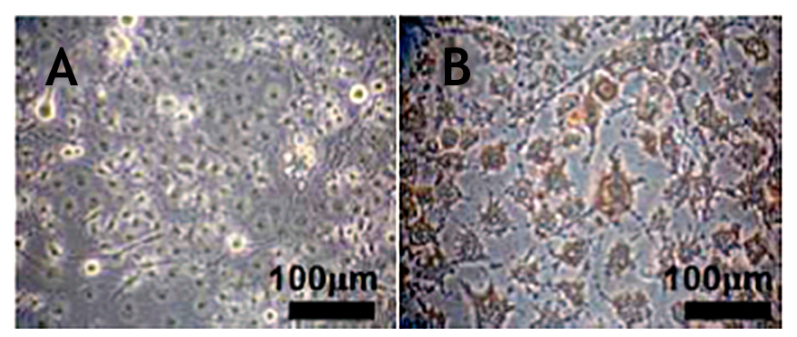

Figura 1. Microscopia ótica mostrando a morfologia de células da linhagem U-251 sem o tratamento com as NPAg (A) e após o tratamento de $200 \mathrm{mg} / \mathrm{mL}$ das NPAg (B). Adaptado de Asharani ${ }^{11}$.
Com relação às vias de exposição, a inalatória é a preferencial de exposição do trato respiratório, sendo o pulmão o órgão alvo por essa via, envolvendo não só as células epiteliais pulmonares, mas também células do sistema imune, macrófagos e fibroblastos, que desempenham papel fundamental no efeito tóxico ocasionado pelas nanopartículas. Essas células têm relação específica com quadros patológicos inflamatórios, fibrose e genotoxicidade induzidos por esses nanomateriais 36,39 .

Nanopartículas contidas em cosméticos e em produtos de uso pessoal representam também um alvo de exposição para a pele e muitas vezes conseguem atingir a circulação sistêmica, em que diversos órgãos podem ser acometidos, como o fígado, rins, coração, tornando-se órgãos alvo. 0 fígado é um órgão muito especial, pois é responsável pela metabolização de xenobióticos com posterior detoxificação, desempenhando função primordial na defesa contra agentes nocivos, pois qualquer injúria hepática provocada pelos nanomateriais pode ser induzida por mecanismos diferentes, como ativação do citocromo P450 ${ }^{36,39}$. Além disso, as NPAg podem se acumular no fígado e baço, ocasionando desequilíbrio dos fatores do sistema imunológico após atingirem a circulação sistêmica ${ }^{40}$, como alteração no perfil de citocinas, ativação do sistema complemento, bem como efeitos in vivo que também são relevantes ${ }^{36,39}$.

A geração exacerbada de ROS parece ser essencial para o efeito tóxico das NPAgs, uma vez que desequilibra o metabolismo celular, através da promoção da inflamação, de danos relacionados às proteínas, membranas e também ao DNA, além de diminuir a função mitocondrial ${ }^{41,42,43}$. O processo de internalização é evidenciado na figura 2.

Com relação ao dano ao material genético celular (DNA), alguns testes in vitro têm sido regulados pelas agências sanitárias internacionais, mas os resultados de genotoxicidade são muitas vezes controversos na literatura, uma vez que o tamanho da nanopartícula é fator crítico para a toxicidade em respostas biológicas ${ }^{41,44}$. Alguns estudos de NPAg revestidas re-

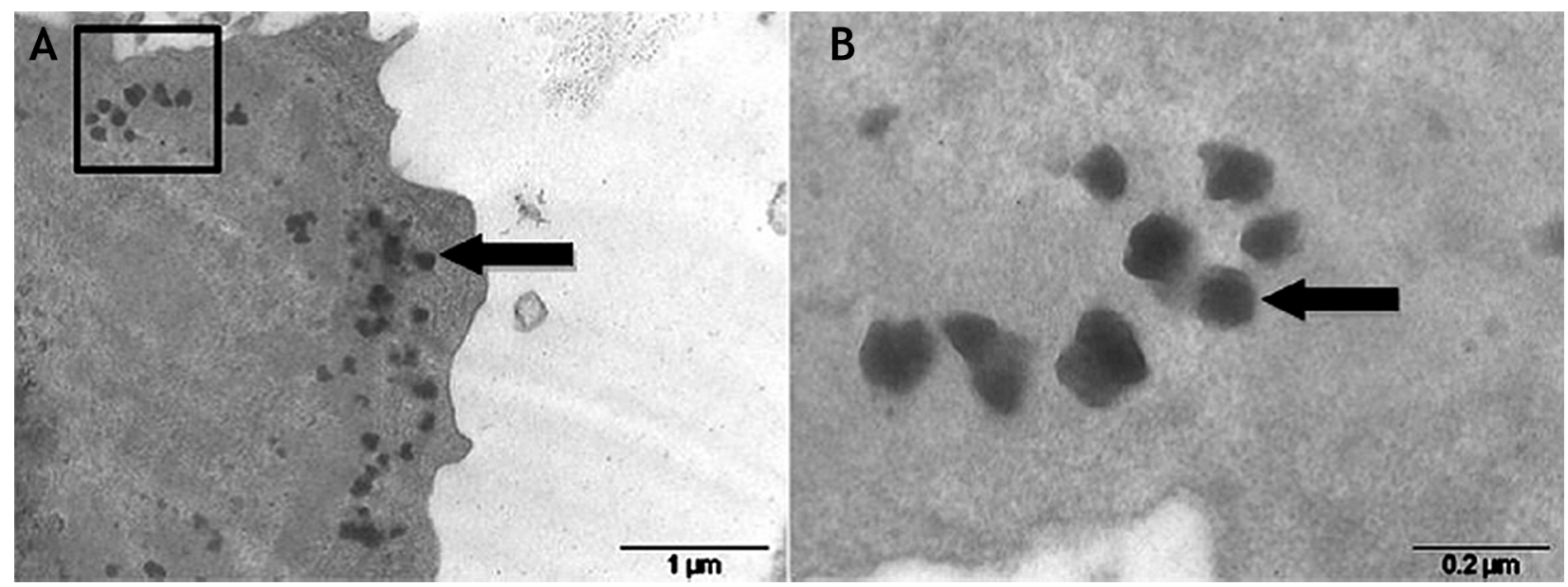

Figura 2. Internalização celular de NPAg em células de macrófagos de rato da linhagem RAW 264.9, após 3 horas de incubação. A) A internalização é visualizada por microscopia de transmissão eletrônica; B) Imagem ampliada das NPAg. Adaptado de Singh ${ }^{48}$. 
lataram não haver efeito genotóxico em tipos celulares diversos, acima de concentrações de 10 mmicrogramas. $\mathrm{mL}^{-1}$, cujo diâmetro variou entre $6 \mathrm{~nm}$ e $80 \mathrm{~nm}{ }^{10,35,45}$. Por outro lado, estudos confirmam o potencial genotóxico das NPAg, com tamanho médio de $1,5 \mathrm{~nm}$ até $70 \mathrm{~nm}$, para células humanas ${ }^{11,46,47}$.

Segundo dados da literatura sobre a cito e genotoxicidade de NPAg em leucócitos sanguíneos humanos, as NPs causaram indução da apoptose, após alcançarem a circulação sanguínea, e inibiram a expressão de citocinas, do interferon e do fator de necrose tumoral alfa ${ }^{46,47}$. Outros dados de citotoxicidade in vitro da literatura ainda reportam que macrófagos da linhagem RAW 264.7 induziram apoptose, após incubação com 30 mmicrogramas. $\mathrm{mL}^{-1}$ de NPAgs por $24 \mathrm{~h}{ }^{48}$. Além disso, a exposição às NPAg $\left(5 \mathrm{mg} \cdot \mathrm{mL}^{-1}\right)$ durante $6 \mathrm{~h}$ em células da linhagem THP1 (células humanas de leucemia monocítica aguda) induziu um aumento significativo de ROS, que se correlacionava com a quebra do DNA e com elevados níveis de indução de necrose e apoptose ${ }^{49}$.

As tabelas 1 e 2 mostram as principais evidências de efeitos tóxicos relacionados à crescente exposição às NPAg, em testes in vitro e in vivo, respectivamente:

\section{Descarte das nanopartículas de prata no ambiente}

Atualmente, os nanomateriais industrializados podem ser considerados a principal fonte de aporte desses materiais no ambiente ${ }^{60}$, aumentando os riscos de se tornarem biodisponíveis e causarem toxicidade e desequilíbrio ambiental. São várias as vias pelas quais as nanopartículas podem impactar o ambiente: (1) efeito tóxico direto sobre a biota; (2) alteração da biodisponibilidade de agentes tóxicos e de nutrientes; e (3) efeitos indiretos causados pela sua interação com os compostos orgânicos naturais'.

$\mathrm{O}$ aporte de nanopartículas no ambiente pode ser causado por fontes naturais e/ou antrópicas ${ }^{61}$. Muitos processos geológicos e biológicos lançam as nanopartículas no ambiente, e como exemplo de um processo natural pode-se citar a poeira vulcânica e a degradação de material biológico ${ }^{62}$. Já as fontes antrópicas englobam as nanopartículas manufaturadas para incorporação em materiais ${ }^{62} \mathrm{e}$ nanopartículas não manufaturadas, provenientes principalmente da queima de combustíveis fósseis ${ }^{63}$.

A prata é considerada relativamente tóxica para o homem ${ }^{64}$ e para a biota ${ }^{65}$, e até a década de 1970 a maior contribuição antrópica de contaminação ambiental desse elemento era advinda da indústria fotográfica ${ }^{66}$. Os íons de prata são persistentes no ambiente, podendo concentrar nos organismos, uma vez que podem ser transportados através da membrana celular.

O aumento da produção comercial de NPAg poderá levar a um acúmulo de espécies de prata em vários compartimentos ambientais com impactos negativos aos ecossistemas. As NPAg podem ser descartadas no ambiente durante sua síntese, durante todo o processo de sua incorporação em produtos comercializáveis, e durante o uso e deposição final de tais produtos ${ }^{67}$. Quando descartadas nos efluentes domésticos e industriais, as nanopartículas de prata poderão atingir os sistemas de tratamento de esgoto convencionais. Sem o conhecimento prévio do tratamento adequado para esse tipo de resíduo, o efluente poderá ser descartado no ambiente de forma não adequada, causando perturbação e desequilíbrio nos ecossistemas aquáticos ${ }^{68}$.

\begin{tabular}{|c|c|c|c|c|}
\hline Tipo celular & Tamanho das NPs (nm) & Concentração & Toxicidade in vitro & Referência \\
\hline $\begin{array}{l}\text { IMR-90 (Fibroblasto de pulmão } \\
\text { humano) e U251 (células } \\
\text { humanas de glioblastoma) }\end{array}$ & $6-20$ & 50 a $400 \mu \mathrm{g} \cdot \mathrm{mL}^{-1}$ & $\begin{array}{l}\text { Induz dano ao DNA (ensaio do cometa) e } \\
\text { formação de micronúcleo }\end{array}$ & 11 \\
\hline $\begin{array}{l}\text { A549 (Adenocarcinoma } \\
\text { humano de pulmão) }\end{array}$ & $30-50$ & Acima de $15,0 \mu \mathrm{g} \cdot \mathrm{mL}^{-1}$ & $\begin{array}{l}\text { Induz estresse oxidativo e formação de } \\
\text { adutos de DNA }\end{array}$ & 35 \\
\hline $\begin{array}{l}\text { THP-1 (leucemia monocítica } \\
\text { humana) }\end{array}$ & 69 & Acima de $7,5 \mu \mathrm{g} \cdot \mathrm{mL}^{-1}$ & Induz apoptose e estresse oxidativo & 49 \\
\hline Célula-tronco mesenquimal & 46 & Acima de $10,0 \mu \mathrm{g} \cdot \mathrm{mL}^{-1}$ & Genotoxicidade (ensaio do cometa) & 50 \\
\hline $\begin{array}{l}\text { Caco-2 (carcinoma } \\
\text { cólon humano) eC } 3 \mathrm{~A} \\
\text { (hepatoma humano) }\end{array}$ & 35 & $\begin{array}{l}\text { Acima de } 1,0 \mu \mathrm{g} \cdot \mathrm{mL}^{-1} \\
\left(\mathrm{DL}_{50}=50 \mu \mathrm{g} \cdot \mathrm{mL}^{-1}\right)\end{array}$ & $\begin{array}{l}\text { Citotoxicidade avaliada pela liberação da } \\
\text { enzima lactato desidrogenase (LD) }\end{array}$ & 51 \\
\hline $\begin{array}{l}\text { HepG2 (carcinoma } \\
\text { hepatocelular humano) }\end{array}$ & $7-20$ & Acima de $250,0 \mu \mathrm{g} \cdot \mathrm{mL}^{-1}$ & $\begin{array}{l}\text { Indução de apoptose;aumento dos níveis } \\
\text { de estresse oxidativo }\end{array}$ & 52 \\
\hline $\begin{array}{l}\text { HeLa (carcinoma cervical } \\
\text { humano) }\end{array}$ & $2-5$ & Acima de $120,0 \mu \mathrm{g} \cdot \mathrm{mL}^{-1}$ & $\begin{array}{l}\text { Indução de apoptose e aumento do } \\
\text { estresse oxidativo }\end{array}$ & 53 \\
\hline $\begin{array}{l}\text { Células hepáticas humanas } \\
\text { derivadas de tecidos não } \\
\text { malignos }\end{array}$ & $5-10$ & $4,0 \mu \mathrm{g} \cdot \mathrm{mL}^{-1}$ & $\begin{array}{l}\text { Indução de apoptose, dano ao DNA } \\
\text { (ensaio do cometa), aumento do estresse } \\
\text { oxidativo com níveis de peroxidação } \\
\text { lipídica aumentados }\end{array}$ & 54 \\
\hline L929 (fibroblastos murinos) & $50-100$ & 25,50 e $100,0 \mu \mathrm{g} \cdot \mathrm{mL}^{-1}$ & $\begin{array}{l}\text { Indução de apoptose e parada do ciclo } \\
\text { celular na fase } G_{2} / M\end{array}$ & 55 \\
\hline $\begin{array}{l}\text { HT } 29 \\
\text { (câncer de cólon humano) }\end{array}$ & 172,6 & Acima de $48,0 \mu \mathrm{g} \cdot \mathrm{mL}^{-1}$ & $\begin{array}{l}\text { Indução de apoptose Fragmentação de } \\
\text { DNA aumentada e despolarização de } \\
\text { membrana mitocondrial }\end{array}$ & 56 \\
\hline
\end{tabular}




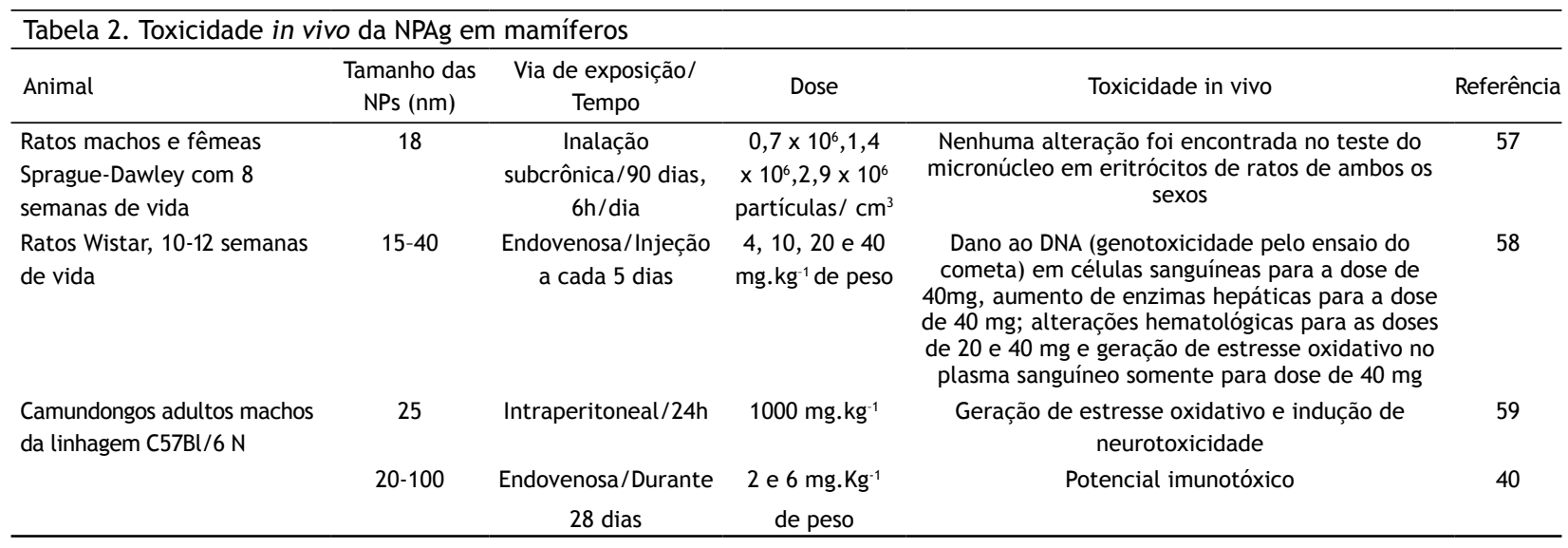

Ainda nos efluentes, as NPAg poderão sofrer transformações, como a aquisição de radicais de enxofre e posterior formação de compostos de sulfeto de prata $\left(\mathrm{Ag}_{2} \mathrm{~S}\right)$, que, dependendo das condições ambientais, poderão ser estáveis o suficiente para evitar a oxidação do enxofre (S) e subsequente liberação de íons de prata.

Após o tratamento de águas residuárias, as NPAg passam a incorporar o lodo resultante do processo de tratamento de efluentes ${ }^{69}$, que poderá ser destinado ao reuso como fertilizante de solos ${ }^{70}$ ou simplesmente ser incinerado ${ }^{18}$, disponibilizando novamente a prata para o ambiente. Assim, como deposição final, o destino do lodo irá afetar a quantidade de NPAg que cada compartimento ambiental irá receber.

Após sua entrada no ambiente, as NPAg poderão sofrer uma variedade de modificações de suas propriedades, que irão interferir no seu comportamento no ambiente, como transporte, destino e potencial de toxicidade. Tais modificações precisam ser consideradas para avaliar o grau de impacto ambiental que essas nanopartículas podem causar.

\section{Comportamento e transformações das nanopartículas de prata no ambiente aquático}

O comportamento de uma nanopartícula não depende somente de suas características, mas também de sua interação com fatores abióticos e bióticos no ambiente, os quais irão determinar a sua biodisponibilidade e o seu comportamento 71. Além disso, devem ser consideradas as várias formas com que as partículas podem se apresentar após o contato com o ambiente ou organismos vivos, podendo estar presentes em sua forma livre ou em aglomerados ${ }^{72}$ (figura 3 ).

Sabe-se que as NPAg têm comportamento diferente nos vários compartimentos ambientais, assim como nos meios de cultivo utilizados nos testes de toxicidade. As diferenças no $\mathrm{pH}$, na estabilidade da força iônica e nas concentrações e tipos de material orgânico presentes são algumas das características que irão influenciar o comportamento, a biodisponibilidade e a toxicidade das NPAg ${ }^{74}$.

Nos ecossistemas aquáticos, as NPAg poderão sofrer vários processos que irão interferir na sua rota, assim como na dose
Principais interações das nanopartículas no ambiente

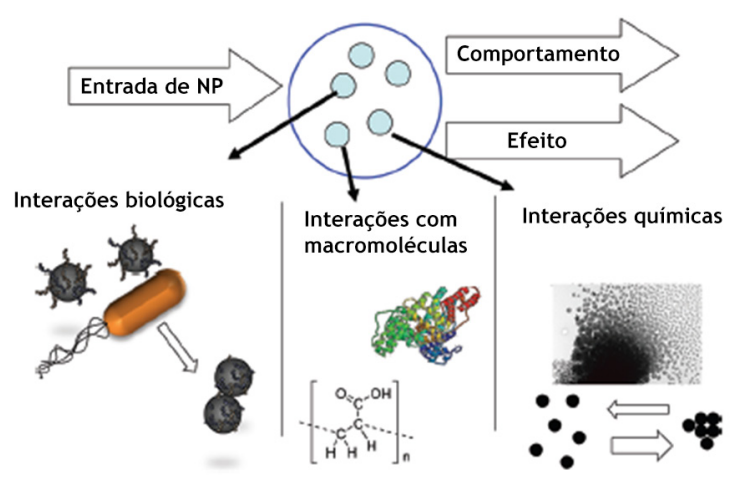

Figura 3. Possíveis transformações das nanopartículas no ambiente. Adaptado de Lowry et $\mathrm{a}^{73}$.

(perda de carga) e na natureza (aglomerada ou dispersa) de exposição ${ }^{75}$. De acordo com Bradford et al. (2009) ${ }^{74}$, nos ecossistemas aquáticos com força iônica elevada as NPAg tendem a permanecer estabilizadas, podendo precipitar e acumular no sedimento. Já em condições ambientais em que as NPAg não são termodinamicamente estáveis ${ }^{76,77}$, poderão ocorrer reações com ligantes inorgânicos e orgânicos, como radicais de enxofre, cloro e matéria orgânica ${ }^{78}$.

As interações entre as nanopartículas de prata e a matéria orgânica natural ou as macromoléculas biológicas irão afetar sua dispersão e características superficiais ${ }^{79}$. Assim, nos ambientes aquáticos, as NPAg podem sofrer agregação afetando seu comportamento, transformação e impacto ambiental.

Outro fator importante que precisa ser levado em conta é que as NPAg industrializadas já estão, geralmente, estabilizadas através de adsorção ou ligações covalentes com compostos orgânicos (em estruturas do tipo core-shell) antes de sua entrada no ambiente ${ }^{80}$. Existem vários tipos de revestimentos usados para estabilizar as NPAg, incluindo ácidos carboxílicos, polímeros, polissacarídeos e surfactantes. A estabilização estérica devido à adsorção de compostos orgânicos pode ser limitada, pois a habilidade de um polímero em estabilizar 
uma nanopartícula irá depender da massa e da conformação da camada adsorvida, e da distribuição do peso molecular do polímero ${ }^{81}$. De acordo com Fabrega et al. $^{75}$, por exemplo, os ácidos húmicos com concentrações superiores a $10 \mathrm{mg} \cdot \mathrm{L}^{-1}$ tendem a estabilizar as nanopartículas, evitando sua agregação.

As NPAg sem revestimentos também podem ser eletronicamente estabilizadas contra agregação por conta de sua carga superficial negativa. Essas nanopartículas eletrostaticamente reduzidas podem ter suas forças repulsivas reduzidas pela presença de contraíons na solução ${ }^{82}$. Portanto, a carga superficial das nanopartículas é influenciada pelas forças eletrostáticas e está intimamente relacionada com seu estado de deposição e agregação.

No ambiente aquático, as concentrações variadas de íons podem alterar a estabilidade das NPAg. A força iônica de ambientes de água doce pode variar de aproximadamente $1 \mathrm{mM} \mathrm{a}$ $10 \mathrm{mM}$ e de aproximadamente $700 \mathrm{mM}$ para ambientes salinos. Portanto, as NPAg tendem a apresentar instabilidade nesses ambientes e a formar espécies orgânicas e inorgânicas, afetando sua mobilidade, biodisponibilidade e toxicidade ${ }^{83,84}$. Um dos maiores riscos das NPAg é sua oxidação e formação de íns $\left(\mathrm{Ag}^{+}\right)$. Os íons de prata podem formar complexos com uma base fraca ou com a matéria orgânica. Assim, nos ambientes aquáticos pode ocorrer formação de sulfeto de prata $\left(\mathrm{Ag}_{2} \mathrm{~S}\right)$, cloreto de prata $(\mathrm{AgCl})$, carbonato de $\left(\mathrm{AgCO}_{3}\right)$ e complexos com a matéria orgânica natural (Ag-MON) ${ }^{82}$ (Figura 4 ).

Baseado no comportamento termodinâmico, o sulfeto de prata $\left(\mathrm{Ag}_{2} \mathrm{~S}\right)$ e o cloreto de prata $(\mathrm{AgCl})$ são as espécies inorgânicas mais relevantes em que as NPAgs podem se transformar no ambiente. Assim, em ambientes de água doce, $\mathrm{Ag}_{2} \mathrm{~S}$, $\mathrm{AgCl}$ e "core- $\mathrm{Ag}^{0}$ " são as espécies mais frequentes, enquan- to em ambientes salobros as espécies mais comuns são $\mathrm{AgCl}$ e "core-Ag" 82 .

Do ponto de vista ambiental, a dissolução de NPAg na presença de íons de cloro parece estar relacionada com a razão $\mathrm{Cl} / \mathrm{Ag}$. Assim, em ambientes marinhos onde a razão de $\mathrm{Cl} / \mathrm{Ag}$ é alta, predominam as formas $\mathrm{AgCl}_{(\text {aq) }}$ e $\mathrm{AgCl}_{2}$, assim como $\mathrm{AgCl}_{3}{ }^{2}$. e $\mathrm{AgCl}_{4}{ }^{3-}$. Já em ambientes de água doce, onde a razão $\mathrm{Cl} / \mathrm{Ag}$ é menor, ocorre frequentemente a formação de $\mathrm{AgCl}$ que tende a precipitar ${ }^{82}$. Com relação à presença de enxofre, as NPAg, assim como outras espécies de prata, reagem fortemente com o enxofre de ambientes aquáticos e atmosféricos, tanto em condições aeróbicas quanto anaeróbicas. Ainda, quando se avalia a solubilidade da prata em condições aeróbicas, é importante também considerar a presença de nanopartículas na forma de óxidos de prata, pois estes dissolvem mais rapidamente em água pura, resultando na descarga de íons de prata $\left(\mathrm{Ag}^{+}\right)^{82}$.

\section{Biodisponibilidade e toxicidade das nanopartículas de prata no ambiente aquático}

Os processos que envolvem a bioacumulação e a biodisponibilização de nanopartículas são o resultado de um conjunto de fatores combinados, como: concentração; características químicas e físicas das nanopartículas e do ambiente; rota de exposição; e a biologia e a ecofisiologia dos organismos envolvidos. Assim, a biodisponibilidade e a bioacumulação das NPAg dependem do tamanho, da forma, da composição química, da carga, da área e estrutura superficial, solubilidade e estado de agregação ${ }^{12}$. Essas propriedades sofrem interferência do meio, sendo necessária, portanto, a caracterização das nanopartículas nos meios de cultivo usados nos testes toxicológicos, assim como no ambiente ${ }^{86}$.

\section{Core}

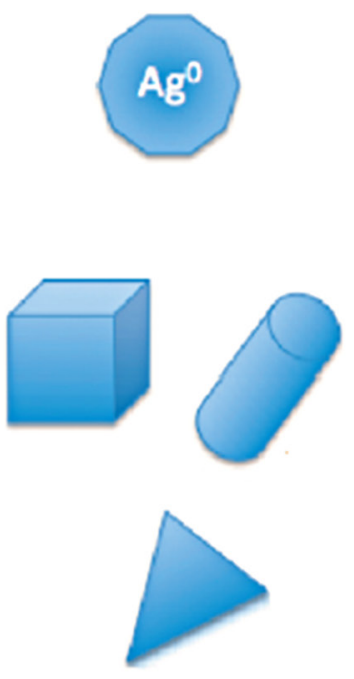

NP-Ag Core-Shell

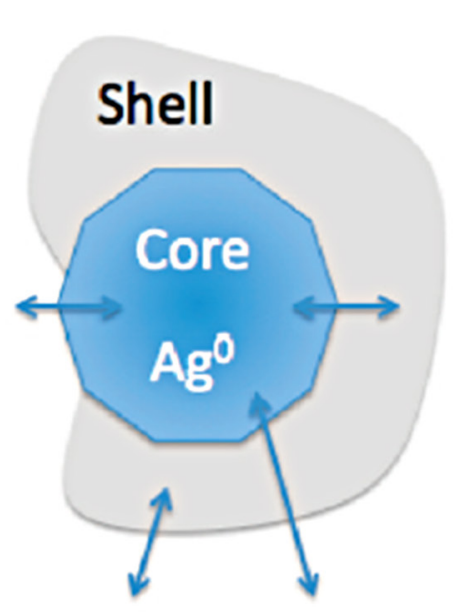

Ambiente
Shell

\section{Orgânico}<smiles>C=C1CCCN1C(=O)[O-]</smiles>

\section{Inorgânico \\ $\left(\mathrm{Ag}_{2} \mathrm{~S}\right)$ \\ (AgCl)}

Figura 4. Estrutura típica de uma NPAg “Core-Shell” passível de ser lançada no ambiente. Adaptado de Levard85. 
Apesar de a biodisponibilidade das NPAg ainda não estar totalmente esclarecida, sabe-se que a prata iônica $\left(\mathrm{Ag}^{+}\right)$ é a forma de maior potencial toxicológico em ecossistemas aquáticos ${ }^{87}$. Nesses ambientes, a prata pode se apresentar livre ou interagir com vários ligantes orgânicos e inorgânicos, sendo sua especiação influenciada pelas propriedades físicas e químicas do ambiente, o que irá determinar o seu potencial de toxicidade ${ }^{88}$.

A bioacumulação e a biodisponibilidade das nanopartículas, em geral, estão associadas a sua capacidade de interagir com a superfície externa de um organismo e/ou ser internalizada. Existem evidências de que as NPAg são capazes de atravessar a parede celular de alguns organismos. Lee ${ }^{89}$ e Asharani ${ }^{14}$, por exemplo, usando imagens de microscopia eletrônica de transmissão (TEM), verificaram que as NPAg associadas a compostos orgânicos podem ser internalizadas por células de peixe. Fábregas ${ }^{90}$ e Xu ${ }^{91}$ também observaram a captura de NPAg pelas bactérias através de imagens de TEM. Esses resultados comprovam a viabilidade das NPAg de penetrarem através de membranas semipermeáveis ${ }^{89,92}$.

Outro processo pouco estudado, mas de grande relevância pelo qual as NPAg podem ser translocadas através da membrana, é a endocitose ${ }^{6}$, processo em que partículas e moléculas entre 1-100 nm são capturadas por evaginação da membrana e transportadas no citoplasma por vesículas.

As NPAg usadas em produtos comercializáveis são, geralmente, encapsuladas com compostos orgânicos para melhor dispersão. Esses grupos funcionais podem influenciar na translocação pela membrana celular ou afetar as propriedades das nanopartículas envolvidas na biodisponibilidade ${ }^{82}$. Em relação às condições ambientais, o pH, a força iônica, a temperatura e as concentrações de matéria orgânica irão afetar a estabilidade e agregação das nanopartículas com consequências para a biodisponibilidade ${ }^{88}$. Tal fato pode ser visualizado na figura 5 , onde as imagens de microscopia de transmissão eletrônica (TEM) demonstram a biodisponibilização das NPAg associadas a compostos orgânicos como proteínas (BSA) e ácidos húmicos.

A solubilidade das NPAg irá determinar de forma proporcional a exposição dos organismos à prata metálica $\left(\mathrm{Ag}^{0}\right)$, à prata iônica $\left(\mathrm{Ag}^{+}\right)$ou aos complexos com prata ${ }^{78}$. Como já citado, a
A

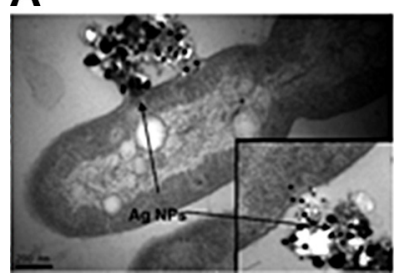

B

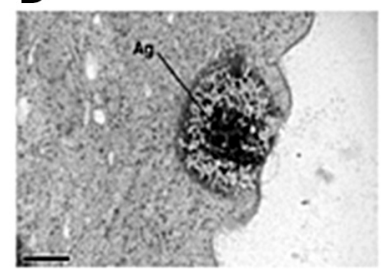

Figura 5. Microscopia de transmissão eletronônica (TEM) mostrando a internalização de NPAg. A) Pseudomonas putida após $24 \mathrm{~h}$ de exposição em suspensão contendo $2 \mathrm{mg} \mathrm{\textrm {L } ^ { - 1 }}$ de NPAg com $10 \mathrm{mg} \mathrm{L}^{-1}$ substância húmica ${ }^{90}$. B) Tecido branquial de truta após 10 dias de exposição em $100 \mu \mathrm{g} \mathrm{L}^{-1}$ de NPAg ${ }^{92}$ concentração de matéria orgânica está diretamente relacionada com a estabilidade e solubilidade das nanopartículas e, consequentemente, com a sua toxicidade. Gao ${ }^{93}$ verificou que a toxicidade de NPAg em Ceriodaphnia dubia foi menor em ambientes com concentrações mais elevadas de substâncias húmicas. Os autores concluíram que a diminuição da toxicidade era consequência de uma menor concentração de íons de prata liberados pelas nanopartículas na presença da matéria orgânica, ou seja, ocorreu uma redução da biodisponibilidade devido à diminuição da solubilidade da prata. Resultados similares foram encontrados por Liu e Hurt ${ }^{78}$, que verificaram uma diminuição da liberação de íons de prata quando as nanopartículas estavam encapsuladas com citrato e ácidos húmicos e fúlvicos. No entanto, para Fábregas et al. ${ }^{75,90}$, a influência de materiais orgânicos na toxicidade de NPAg vai além da solubilidade de íons. De acordo com esses autores, quando ocorre o encapsulamento das NPAg por materiais orgânicos, as características físicas e químicas das nanopartículas mudam e, consequentemente, sua toxicidade.

Outro fator importante a ser considerado é a agregação das nanopartículas, que irá determinar o tamanho efetivo da partícula à qual os organismos serão expostos, influenciando sua biodisponibilidade e toxicidade. De acordo com Navarro ${ }^{12}$, quanto mais agregadas as nanopartículas, menor sua área superficial específica e menor sua biodisponibilidade e seu potencial toxicológico. Vários outros estudos têm demonstrado que a agregação de nanopartículas diminui a toxicidade para a biota ${ }^{74,81,94}$. No entanto, para Ward e Kach ${ }^{95}$, a observação de que o aumento das nanopartículas por agregação está relacionado com uma diminuição da toxicidade é válido somente para organismos em que a principal via de captura das nanopartículas ocorre diretamente através da membrana. Para os organismos em que a captura ocorre primeiramente através da ingestão alimentar de grandes partículas, observa-se um aumento na biodisponibilidade.

Mesmo para os organismos em que a captura das nanopartículas ocorre através da membrana, a toxicidade pode estar relacionada não necessariamente com o tamanho, mas com o aumento de elementos tóxicos carreados pelos agregados e que são passíveis de causar dano celular. De acordo com Reinsch ${ }^{96}$, as NPAg agregadas têm um efeito inibitório maior sobre o crescimento de $E$. coli do que aquelas dispersas no meio, devido provavelmente aos radicais de enxofre presentes nos agregados.

A carga superficial das NPAg é outro fator extremamente importante para toxicidade celular. No caso de bactérias, por exemplo, que têm parede celular carregada negativamente, as NPAg encapsuladas com cargas positivas foram as responsáveis pela inibição do crescimento. Para esse grupo de organismo dois mecanismos de toxicidade de NPAg já foram propostos:

1) Estresse oxidativo, como consequência da formação de espécies reativas de oxigênio (ROS) e que potencialmente são formadas na superfície das NPAg ${ }^{27,97}$;

2) Interação dos íons de prata, liberados das nanopartículas, com grupos tióis de enzimas e proteínas metabolicamente 
importantes, afetando a respiração celular e o transporte de íons através da membrana e, consequentemente, culminando em morte celular ${ }^{87,88,98,99}$.

O estado de oxidação das NPAg também está relacionado com sua toxicidade, sendo a oxidação de NPAg e sua subsequente dissolução na forma de íons de prata a causa mais importante de toxicidade desses compostos em diferentes organismos ${ }^{100}$. No entanto, em ambientes aquáticos a biodisponibilidade e toxicidade de íons $\mathrm{Ag}^{+}$é atenuada pela presença de enxofre e formação de $\mathrm{Ag}_{2} \mathrm{~S}$ relativamente estável e insolúvel ${ }^{65,101}$.

Apesar da extensa pesquisa sobre a toxicidade da prata na biota aquática (tabela 3), pouco se sabe a respeito dos efeitos das NPAg sobre esses organismos. Alguns trabalhos têm indicado que as concentrações de NPAg encontradas em ambientes aquáticos não afetam o crescimento e a eficiência fotossintética de algas como Thalassiosira sp ${ }^{102}$. Os autores verificaram que a toxicidade ocorre somente quando há liberação de íons de prata $\left(\mathrm{Ag}^{+}\right)$. Resultados contrários foram encontrados por Navarro ${ }^{13}$, que ao estudar os efeitos tóxicos de NPAg em Chlamydomonas reinnhardi observou maior toxicidade causada pelas nanopartículas em relação a sua forma iônica.

Em relação aos organismos invertebrados, os dados da literatura têm demonstrado que as NPAg são passíveis de causar toxicidade 103,104; no entanto, essa é menor do que a causada pelos íos de prata ${ }^{94}$. Da mesma forma que para os outros grupos de organismos, o tipo de NPAg, a força iônica e a concentração de moléculas orgânicas irão influenciar na toxicidade. Kvitek ${ }^{94}$, por exemplo, verificou que as NPAg encapsuladas com Tween 80 eram mais estáveis; no entanto, causaram toxicidade ao ciliado Paramecium caudatum.

Alguns estudos de toxicidade realizados com peixe demonstraram que as NPAg com tamanho entre 10-80 nm afetaram os estágios iniciais de desenvolvimento desses organismos, como deformidade na coluna espinhal, arritmia cardíaca e sobrevivência ${ }^{92,105,106}$. Também foi observado estresse oxidativo e acúmulo das nanopartículas nas guelras e fígado desses or- ganismos ${ }^{92,106}$. De maneira geral, os estágios juvenis dos peixes se mostraram mais susceptíveis às NPAg do que a mesma concentração de prata adicionada na forma de $\mathrm{AgNO}_{3}$. Para o mesmo grupo de organismos, Yeo e Yoon ${ }^{107}$ verificaram que as NPAg agregadas foram incorporadas nos vasos sanguíneos, pele, cérebro e coração, enquanto os íons de prata se concentraram nas organelas e núcleo. Uma vez bioacumuladas nos peixes, as NPAg ficam disponíveis para os próximos níveis tróficos, sendo, assim, passíveis de serem adquiridas pelo homem via alimentação ${ }^{108}$.

\section{Segurança de Nanomateriais Manufaturados: Regulação Internacional para Nanopartículas de Prata}

No Brasil, alguns esforços têm sido relatados em busca da divulgação de informações, promoção de debates entre a sociedade, as autoridades sanitárias, universidades e as indústrias, a respeito da temática da nanotoxicologia. Além disso, tem sido amplamente questionada a adequação dos sistemas regulatórios nacionais e internacionais para os produtos contendo algum tipo de nanomaterial. Esse novo posicionamento tem proporcionado o desenvolvimento de novas pesquisas no âmbito da nanotoxicologia com o aumento de aportes financeiros para pesquisas, a fim de garantir a proteção, segurança e saúde ${ }^{112}$.

$\mathrm{O}$ número de produtos contendo nanomateriais tem aumentado constantemente no mercado (passou de $30 \mathrm{em} 2006$ para 300 no ano de 2011, e atualmente é superior a 1.000) ${ }^{113}$, apresentando um lucro de 50 bilhões de dólares no ano de $2006{ }^{114}$. Estima-se que em torno de 1.120 toneladas serão produzidas e comercializadas em $2015^{115,116}$. Com isso, observamos que não existem requisitos mínimos para a regulação desses produtos contendo nanomaterial para posterior comercialização. Isso tem se tornado alvo de intenso debate na comunidade científica, bem como de grande preocupação das autoridades sanitárias na avaliação dos eventuais riscos, tanto

\begin{tabular}{|c|c|c|c|}
\hline Organismo-teste & Tamanho da nanopartícula (nm) & Concentração nominal/tempo de exposição & Referência \\
\hline Daphnia magna & 57,6 & $121 \mu \mathrm{g} \cdot \mathrm{L}^{-1} / 48 \mathrm{~h}$ & 109 \\
\hline Daphnia pulex & 57,6 & $8,45 \mu \mathrm{g} \cdot \mathrm{L}^{-1} / 48 \mathrm{~h}$ & \\
\hline Daphnia pulex & $20-30$ & $0,04 \mathrm{mg} \mathrm{L}^{-1} / 48 \mathrm{~h}$ & 103 \\
\hline Daphnia galeata & 57,6 & $13,9 \mu \mathrm{g} . \mathrm{L}^{-1} / 48 \mathrm{~h}$ & \\
\hline Danio rerio (embrião) & $5-20$ & $5-100 \mathrm{mg} \mathrm{L}^{-1} / 72 \mathrm{~h}$ & 14 \\
\hline Danio rerio (adulto) & 26,6 & $1.000 \mathrm{mg} \mathrm{L}^{-1} / 48 \mathrm{~h}$ & 105 \\
\hline Danio rerio (adulto) & $5-46$ & $0,19-0,71 \mathrm{nM} / 120 \mathrm{~h}$ & 110 \\
\hline Oncorhychus mykiss & $3-4$ & $10-20 \mathrm{mg} \cdot \mathrm{L}^{-1} / 48 \mathrm{~h}$ & 111 \\
\hline Thalassiosira weisfflogii & $60-70$ & $0,2-103 \mathrm{mM}$ & 102 \\
\hline Paramacium caudatum & $30-40$ & $39 \mathrm{mg} \cdot \mathrm{L}^{-1} / 1 \mathrm{~h}$ & 94 \\
\hline C. reinhardii & 25 & $0,1-10 \mu M / 1-5 h$ & 12 \\
\hline $\begin{array}{l}\text { Pseudokirchneriella } \\
\text { subcapitata }\end{array}$ & $20-30$ & $0,19 \mathrm{mg} \mathrm{L}^{-1} / 96 \mathrm{~h}$ & 103 \\
\hline Ceriodaphnia dubia & $20-30$ & $0,46 \mathrm{mg} \mathrm{L}^{-1} / 48 \mathrm{~h}$ & 93 \\
\hline
\end{tabular}


à saúde quanto ao meio ambiente, envolvidos no consumo com posterior descarte desses produtos.

Dessa forma, defender a saúde pública e o ambiente acima dos interesses do mercado tornou-se um desafio muito grande das agências sanitárias e do público em geral, em todo o mundo. Somado a isso, torna-se necessário o esclarecimento da população quanto à probabilidade do risco do consumo desses produtos contendo nanomateriais, visto que o Código de Defesa do Consumidor no Brasil, regulamentado pela Lei $8078 / 90$, estabelece como direitos básicos do consumidor a proteção e a saúde contra eventuais riscos decorrentes do consumo de produtos ${ }^{117}$.

Diante desse quadro, fica evidente a necessidade emergencial da regulação de produtos contendo nanomateriais pelas autoridades sanitárias. No âmbito internacional, alguns países da Europa e os Estados Unidos tomaram determinadas medidas quanto a esse importante assunto. As agências federais dos Estados Unidos que são responsáveis por regular o impacto na saúde e no meio ambiente das NPAg são ${ }^{88}$ : a Agência de Proteção Ambiental (EPA, Environmental Protection Agency), FDA (Food and Drug Administration), que regula alimentos e produtos relacionados aos produtos terapêuticos, e o Instituto Nacional de Saúde e Segurança Ocupacional (NIOSH, National Institute for Occupational Safety and Health). O NIOSH é responsável por evitar doenças, riscos, lesões e mortes relacionadas ao ambiente de trabalho, preconizando limites máximos de exposição ocupacional ${ }^{118}$. A EPA regula a toxicidade das NPAg por meio das seguintes agências: Ação de Controle de Substâncias Tóxicas (Toxic Substances Control Act - TSCA), que regula produtos químicos e é designada a revisar novos produtos que possam representar risco à saúde e ao meio ambiente, antes que sejam comercializados; a FIFRA (the Federal Insecticide, Fungicide and Rodenticide Act), que regula os pesticidas e biocidas ${ }^{119}$, focalizando a regulação dos produtos e não das substâncias ${ }^{120}$. Em abril de 2012, o FDA publicou dois novos projetos de orientações para os fabricantes de alimentos e cosméticos, que também estão abertos para comentários do público ${ }^{114}$.

Com base em todas essas medidas de fiscalização e regulação sanitárias das agências nos Estados Unidos, a comercialização de produtos contendo nanomateriais torna-se limitada, desde que os riscos envolvidos à saúde e ao meio ambiente sejam evidenciados.

\section{Considerações finais}

O conhecimento dos riscos que os nanomateriais causam à saúde pública e ao ambiente é importante para que a sua produção, comercialização e descarte sejam feitos de forma adequada e sustentável. A toxicidade das NPAg é parcialmente explicada pela liberação de íons; no entanto, não está totalmente esclarecido se as NPAg, em si, causam efeito direto de toxicidade, existindo, assim, a necessidade de mais pesquisas sobre o assunto. As informações geradas a partir de estudos científicos são indispensáveis no cenário da política ambien- tal e de saúde pública, e serão importantes como ferramentas para tomada de decisões de âmbito governamental para a implantação de medidas de fiscalização e regulação sanitárias, de investimentos em pesquisas seguras, além de debate aberto de maior impacto social.

\section{Referências}

1. Simonet $B M$, Valcárcel $M$. Monitoring nanoparticles in the environment. Anal Bioanal Chem. 2009;393(1):17-21.

2. Wei L, Thakkar M, Chen Y, Ntim SA, Mitra S, Zhang X. Cytotoxicity effects of water dispersible oxidized multiwalled carbon nanotubes on marine alga Dunaliella tertiolecta. Aquat Toxicol. 2010;100(2):194-201.

3. Gong N, Shao K, Feng W, Lin Z, Liang C, Sun Y. Biotoxicity of nickel oxide nanoparticles and bio-remediation by microalgae Chlorella vulgaris. Chemosphere. 2011;83(4):510-6.

4. Petersen EJ, Zhang L, Mattison NT, O'Carroll DM, Whelton AJ, Uddin N, Nguyen T, Huang Q, Henry TB, Holbrook RD, Chen KL. Potential release pathways, environmental fate, and ecological risks of carbon nanotubes. Environ Sci Technol. 2011;45(23):9837-56.

5. Lapresta-Fernández A, Fernández A, Blasco J. Nanoecotoxicity effects of engineered silver and gold nanoparticles in aquatic organisms. Trends Anal Chem. 2012;32:40-59.

6. Moore MN. Do nanoparticles present ecotoxicological risks for the health of the aquatic environment? Environ Int. 2006;32:967-76.

7. Chen X, Schluesener H J. Nanosilver: a nanoproduct in medical application. Toxicol Lett. 2008;176(1):1-12.

8. Lovern SB, Strickler JR, Klaper R. Behavioral and physiological changes in Daphnia magna when exposed to nanoparticle suspensions (titanium dioxide, nano- $\mathrm{C}_{60}$, and $\mathrm{C}_{60} \mathrm{Hx}$ $\mathrm{C}_{70} \mathrm{Hx}$ ). Environ Sci Technol. 2007;41(12):4465-70.

9. Kümmerer K, Menz J, Schubert T, Thielemans W. Biodegradability of organic nanoparticles in the aqueous environment. Chemosphere. 2011;82(10):1387-92.

10. Lu W, Senapati D, Wang S, Tovmachenko O, Singh AK, Yu H, Ray PC. Effect of surface coating on the toxicity of silver nanomaterials on human skin keratinocytes. Chem Phys Lett. 2010; 487:92-6.

11. AshaRani PV, Low Kah Mun G, Hande MP, Valiyaveettil S. Cytotoxicity and genotoxicity of silver nanoparticles in human cells. ACS Nano. 2009;3(2):279-90.

12. Navarro E, Baun A, Behra R, Hartmann NB, Filser J, Miao AJ, Quigg A, Santschi PH, Sigg L. Environmental behavior and ecotoxicity of engineered nanoparticles to algae, plants, and fungi. Ecotoxicology. 2008;17(5):372-86.

13. Navarro E, Piccapietra F, Wagner B, Marconi F, Kaegi R, Odzak N, Sigg L, Behra R. Toxicity of silver nanoparticles to Chlamydomonas reinhardtii. Environ Sci Technol. 2008;42(23):8959-64.

14. Asharani PV, Lian Wu Y, Gong Z, Valiyaveettil S. Toxicity of silver nanoparticles in zebrafish models. Nanotechnology. 2008;19(25):255102. 
15. Meyer JN, Lord CA, Yang XY, Turner EA, Badireddy AR, Marinakos SM, Chilkoti A, Wiesner MR, Auffan M. Intracellular uptake and associated toxicity of silver nanoparticles in Caenorhabditis elegans. Aquat Toxicol. 2010;100(2):140-50.

16. Sondi I, Salopek-Sondi B. Silver nanoparticles as antimicrobial agent: a case study on E-coli as a model for Gram-negative bacteria. J Colloid Interface Sci. 2004; 275(1):177-82.

17. Roh JY, Sim SJ, Yi J, Park K, Chung KH, Ryu DY, Choi J. Ecotoxicity of silver nanoparticles on the soil nematode $\mathrm{Ca}$ enorhabditis elegans using functional ecotoxicogenomics. Environ Sci Technol. 2009;43(10):3933-40.

18. Gottschalk F, Sonderer T, Scholz RW, Nowack B. Modeled environmental concentrations of engineered nanomaterials (TiO(2), $\mathrm{ZnO}, \mathrm{Ag}, \mathrm{CNT}$, Fullerenes) for different regions. Environ Sci Technol. 2009;43(24):9216-22.

19. Geranio L, Heuberger M, Nowack B. The behavior of silver nanotextiles during washing. Environ Sci Technol. 2009;43(21):8113-8.

20. Yilmaz E, Borchert HH. Effect of lipid-containing, positively charged nanoemulsions on skin hydration, elasticity and erythema--an in vivo study. Int J Pharm. 2006;307(2):232-8.

21. Panacek A, Kvítek L, Prucek R, Kolar M, Vecerova R, Pizúrova N, Sharma VK, Nevecna T, Zboril R. Silver colloid nanoparticles: synthesis, characterization, and their antibacterial activity. J Phys Chem B. 2006;110(33):16248-53.

22. Sarkar J, Chattopadhyay D, Patra S, Deo SS, Sinha S, Ghosh M, Mukherjee A, Acharya K. Alternaria alternata mediated synthesis of protein capped silver nanoparticles and their genotoxic activity. Dig J Nanomat Biostruct. 2011;6(2):563-73.

23. Xiu ZM, Zhang QB, Puppala HL, Colvin VL, Alvarez PJ. Negligible particle-specific antibacterial activity of silver nanoparticles. Nano Lett. 2012;12(8):4271-5.

24. Sotiriou GA, Pratsinis SE. Antibacterial activity of nanosilver ions and particles. Environ Sci Technol. 2010; 44(14):5649-54.

25. Henig RM. Our silver-coated future. Onearth Fall. 2007;22-29.

26. Bhattacharyya S, Kudgus RA, Bhattacharya R, Mukherjee P. Inorganic nanoparticles in cancer therapy. Pharm Res. 2011;28(2):237-59.

27. Kim JS, Kuk E, Yu KN, Kim JH, Park SJ, Lee HJ, Kim SH, Park YK, Park YH, Hwang CY, Kim YK, Lee YS, Jeong DH, Cho MH. Antimicrobial effects of silver nanoparticles. Nanomedicine. 2007;3(1):95-101

28. Lok CN, Ho CM, Chen R, He QY, Yu WY, Sun H, Tam PKH, Chiu JF, Che CM. Silver nanoparticles: partial oxidation and antibacterial activities. J Biol Inorg Chem. 2007;12(4):527-34.

29. Gogoi SK, Gopinath P, Paul A, Ramesh A, Ghosh SS, Chattopadhyay A. Green Fluorescent Protein-Expressing Escherichia coli as a Model System for Investigating the Antimicrobial Activities of Silver Nanoparticles. Langmuir. 2006;22(22):9322-8.

30. Chen J, Han CM, Lin XW, Tang ZJ, Su SJ. Effect of Silver Nanoparticle Dressing on Second Degree Burn Wound. Zhonghua Wai Ke Za Zhi. 2006;44(1):50-2.
31. Samuel U, Guggenbichler JP. Prevention of Catheter-Related Infections: The Potential of a New Nano-Silver Impregnated Catheter. Int J Antimicrob Agents. 2004;23 Suppl 1:S75-8.

32. Lem KW, Choudhury A, Lakhani AA, Kuyate P, Haw JR, Lee DS, Iqbal Z, Brumlik CJ. Use of Nanosilver in Consumer Products. Recent Patents on Nanotechnology. 2012;6(1):60-72.

33. Arora S, Jain J, Rajwade JM, Paknikar KM. Cellular responses induced by silver nanoparticles: In vitro studies. Toxicol Lett. 2008;179(2):93-100.

34. Kim S, Choi JE, Choi J, Chung KH, Park K, Yi J, Ryu DY. Oxidative stress-dependent toxicity of silver nanoparticles in human hepatoma cells. Toxicol In Vitro. 2009;23(6):1076-84.

35. Foldbjerg R, Dang DA, Autrup H. Cytotoxicity and genotoxicity of silver nanoparticles in the human lung cancer cell line, A549. Arch Toxicol. 2011;85(7):743-50.

36. Oberdörster G, Maynard A, Donaldson K, Castranova V, Fitzpatrick J, Ausman K, Carter J, Karn B, Kreyling W, Lai D, Olin S, Monteiro-Riviere N, Warheit D, Yang H. Principles for characterizing the potential human health effects from exposure to nanomaterials: elements of a screening strategy. Part Fibre Toxicol. 2005; 6:2-8.

37. Kreyling WG, Semmler-Behnke M, Moller W. Health implications of nanoparticles. J Nanopart Res. 2006;8:543-62.

38. Sharma HS, Sharma A. Neurotoxicity of engineered nanoparticles from metals. CNS Neurol Disord Drug Targets. 2012;11(1):65-80.

39. Oberdörster G. Nanotoxicology: in vitro-in vivo dosimetry. Environ Health Perspect. 2012;120(1):A13.

40. Schäfer B, Brocke JV, Epp A, Götz M, Herzberg F, Kneuer C, Sommer Y, Tentschert J, Noll M, Günther I, Banasiak U, Böl GF, Lampen A, Luch A, Hensel A. State of the art in human risk assessment of silver compounds in consumer products: a conference report on silver and nanosilver held at the BfR in 2012. Arch Toxicol. 2013. [no prelo].

41. Nel A, Xia T, Mädler L, Li N. Toxic potential of materials at the nanolevel. Science. 2006;311(5761):622-7.

42. Brunner TJ, Wick P, Manser P, Spohn P, Grass RN, Limbach LK, Bruinink A, Stark WJ. In vitro cytotoxicity of oxide nanoparticles: comparison to asbestos, silica, and the effect of particle solubility. Environ Sci Technol. 2006;40(14):4374-81.

43. Soto KF, Carrasco A, Powell TG, Garza KM, Murr LE. Comparative in vitro cytotoxicity assessment of some manufactured nanoparticulate materials characterized by transmission electron microscopy. J Nanopart Res. 2005;7:145-69.

44. Jiang W, Kim BY, Rutka JT, Chan WC. Nanoparticle-mediated cellular response is size-dependent. Nat Nanotechnol. 2008;3(3):145-50.

45. Singh S, D'Britto V, Prabhune AA, Ramana CV, Dhawan A, Prasad BLV. Cytotoxic and genotoxic assessment of glycolipid-reduced and -capped gold and silver nanoparticles. New J Chem. 2010;34:294-301. 
46. Greulich C, Diendorf J, Gessmann J, Simon T, Habijan T, Eggeler G, Schildhauer TA, Epple M, Koller M. Cell type-specific responses of peripheral blood mononuclear cells to silver nanoparticles. Acta Biomater. 2011;7(9):3505-14.

47. Shin SH, Ye MK, Kim HS, Kang HS. The effects of nanosilver on the proliferation and cytokine expression by peripheral blood mononuclear cells. Int Immunopharmacol. 2007;7(13):1813-8.

48. Singh R, Ramarao P. Cellular uptake, intracellular trafficking and cytotoxicity of silver nanoparticles. Toxicol Lett. 2012;213(2):249-59.

49. Foldbjerg R, Olesen P, Hougaard M, Dang DA, Hoffmann HJ, Autrup H. PVP-coated silver nanoparticles and silver ions induce reactive oxygen species, apoptosis and necrosis in THP-1 monocytes. Toxicol Lett. 2009;190(2):156-62.

50. Hackenberg S, Scherzed A, Kessler M, Hummel S, Technau A, Froelich K, Ginzkey C, Koehler C, Hagen R, Kleinsasser N. Silver nanoparticles: evaluation of DNA damage, toxicity and functional impairment in human mesenchymal stem cells. Toxicol Lett. 2011;201(1):27-33.

51. Gaiser BK, Fernandes TF, Jepson MA, Lead JR, Tyler CR, Baalousha M, Biswas A, Britton GJ, Cole PA, Johnston BD, Ju-Nam Y, Rosenkranz P, Scown TM, Stone V. Interspecies comparisons on the uptake and toxicity of silver and cerium dioxide nanoparticles. Environ Toxicol Chem. 2012;31(1):144-54.

52. Jain J, Arora S, Rajwade JM, Omray P, Khandelwal S, Paknikar KM. Silver nanoparticles in therapeutics: development of an antimicrobial gel formulation for topical use. Mol Pharm. 2009; 6(5):1388-401.

53. Miura N, Shinohara Y. Cytotoxic effect and apoptosis induction by silver nanoparticles in HeLa cells. Biochem Biophys Res Commun. 2009;390(3):733-7.

54. Piao MJ, Kang KA, Lee IK, Kim HS, Kim S, Choi JY, Choi J, Hyun JW. Silver nanoparticles induce oxidative cell damage in human liver cells through inhibition of reduced glutathione and induction of mitochondria-involved apoptosis. Toxicol Lett. 2011;201(1):92-100.

55. Wei L, Tang J, Zhang Z, Chen Y, Zhou G, Xi T. Investigation of the cytotoxicity mechanism of silver nanoparticles in vitro. Biomed Mater. 2010;5(4):044103.

56. Sanpui P, Chattopadhyay A, Ghosh SS. Induction of apoptosis in cancer cells at low silver nanoparticle concentrations using chitosan nanocarrier. ACS Appl Mater Interfaces. 2011;3(2):218-28.

57. Kim JS, Sung JH, Ji JH, Song KS, Lee JH, Kang CS, Yu IJ. In vivo Genotoxicity of Silver Nanoparticles after 90-day Silver Nanoparticle Inhalation Exposure. Saf Health Work. 2011;2(1):34-8.

58. Tiwari DK, Jin T, Behari J. Dose-dependent in-vivo toxicity assessment of silver nanoparticle in Wistar rats. Toxicol Mech Methods. 2011;21(1):13-24.

59. Rahman MF, Wang J, Patterson TA, Saini UT, Robinson BL, Newport GD, Murdock RC, Schlager JJ, Hussain SM, Ali SF. Expression of genes related to oxidative stress in the mou- se brain after exposure to silver-25 nanoparticles. Toxicol Lett. 2009;187(1):15-21.

60. Chatterjee R. The continuing uncertainty of nano risks and regulations. Environ Sci Technol. 2008;42(21):7733.

61. Handy RD, von der Kammer F, Lead JR, Hassellov M, Owen $R$, Crane $M$. The ecotoxicology and chemistry of manufactured nanoparticles. Ecotoxicology 2008; 17:287-314.

62. Moore MN. Do nanoparticles present ecotoxicological risks for the health of the aquatic environment? Environ International. 2006;32(8):967-76.

63. Oberdörster G, Oberdörster E, Oberdörster J. Nanotoxicology: an emerging discipline evolving from studies of ultrafine particles. Environ Health Perspect. 2005;113(7):823-39.

64. Sawosz E, Binek M, Grodzik M, Zielinska M, Sysa P, Szmidt $M$, et al. Influence of hydrocolloidal silver nanoparticles on gastrointestinal microflora and morphology of enterocytes of quails. Arch Anim Nutr. 2007;61(6):444-51.

65. Bianchini A, Bowles KC, Brauner CJ, Gorsuch JW, Kramer JR, Wood CM. Evaluation of the effect of reactive sulfide on the acute toxicity of silver (I) to Daphnia magna. Part 2: toxicity results. Environ Toxicol Chem. 2002;21(6):1294-300.

66. Purcell TW, Peters JJ. Sources of silver in the environment. Environ Toxicol Chem 1998; 17:539-546.

67. Köhler AR, Som C, Helland A, Gottschalk F. Studying the potential release of carbon nanotubes throughout the application life cycle. J Cleaner Prod. 2008; 16:927-37.

68. Xing Y, Yang X, Dai J. Antimicrobial finishing of cotton textile based on water glass by sol-gel method. J Sol-Gel Sci Technol. 2007; 43:187-92.

69. Blaser SA, Scheringer M, MacLeod M, Hungerbühler K. Estimation of cumulative aquatic exposure and risk due to silver: contribution of nano-functionalized plastics and textiles. Sci Total Environ. 2008;390(2-3):396-409.

70. Nicholson FA, Smith SR, Alloway BJ, Carlton-Smith C, Chambers BJ. An inventory of heavy metals inputs to agricultural soils in England and Wales. Sci Total Environ. 2003;311(1-3):205-219.

71. Handy RD, van den Brink N, Chappell M, Mühling M, Behra $R$, Dušinská $M$, Simpson $P$, Ahtiainen $J$, Jha $A N$, Seiter J, Bednar A, Kennedy A, Fernandes TF, Riediker M. Practical considerations for conducting ecotoxicity test methods with manufactured nanomaterials: what have we learnt so far? Ecotoxicology. 2012;21(4):933-72.

72. Schwab F, Bucheli TD, Lukhele LP, Magrez A, Nowack B, Sigg L, Knauer K. Are carbon nanotube effects on green algae caused by shading and agglomeration? Environ Sci Technol. 2011;45(14):6136-44.

73. Lowry GV, Gregory KB, Apte SC, Lead JR. Transformations of nanomaterials in the environment. Environ Sci Technol. 2012;46(13):6893-9.

74. Bradford A, Handy RD, Readman JW, Atfield A, Muhling M. Impact of silver nanoparticle contamination on the genetic diversity of natural bacterial assemblages in estuarine sediments. Environ Sci Technol. 2009;43(12):4530-6. 
75. Fabrega J, Fawcett SR, Renshaw JC, Lead JR. Silver nanoparticle impact on bacterial growth: effect of $\mathrm{pH}$, concentration, and organic matter. Environ Sci Technol. 2009;43(19):7285-90.

76. Xiu ZM, Ma J, Alvarez PJ. Differential Effect of Common Ligands and Molecular Oxygen on Antimicrobial Activity of Silver Nanoparticles versus Silver Ions. Environ Sci Technol. 2011;45(20):9003-8.

77. Liu JY, Sonshine DA, Shervani S, Hurt RH. Controlled Release of Biologically Active Silver from Nanosilver Surfaces. ACS Nano. 2010;4(11):6903-13.

78. Liu J, Hurt RH. Ion release kinetics and particle persistence in aqueous nano-silver colloids. Environ Sci Technol. 2010;44(6):2169-75.

79. Lundqvist M, Stigler J, Elia G, Lynch I, Cedervall T, Dawson KA. Nanoparticle size and surface properties determine the protein corona with possible implications for biological impacts. Proc Natl Acad Sci U S A. 2008;105(38):14265-70.

80. Liu W, Zhou Q, Liu J, Fu J, Liu S, Jiang G. Environmental and biological influences on the stability of silver nanoparticles. Chin Sci Bull. 2011;56(19):2009-15.

81. Lok CN, Ho CM, Chen R, He QY, Yu WY, Sun H, Tam PK, Chiu JF, Che CM. Silver nanoparticles: partial oxidation and antibacterial activities. J Biol Inorg Chem. 2007;12(4):527-534.

82. Fabrega J, Luoma SN, Tyler CR, Galloway TS, Lead JR. Silver nanoparticles: Behaviour and effects in the aquatic environment. Environ Int. 2011;37(2):517-31.

83. Huynh KA, Chen KL. Aggregation Kinetics of Citrate and Polyvinylpyrrolidone Coated Silver Nanoparticles in Monovalent and Divalent Electrolyte Solutions. Environ Sci Technol. 2011;45(13):5564-71.

84. Chinnapongse SL, MacCuspie RI, Hackley VA. Persistence of singly dispersed silver nanoparticles in natural freshwaters, synthetic seawater, and simulated estuarine waters. Sci Total Environ. 2011;409(12):2443-50.

85. Levard C, Hotze EM, Lowry GV, Brown GE Jr. Environmental Transformations of Silver Nanoparticles: Impact on Stability and Toxicity. Environ Sci Technol. 2012;46(13):6900-14.

86. Luoma SN, Rainbow PS. Why is metal bioaccumulation so variable? Biodynamics as a unifying concept. Environ Sci Technol. 2005;39(7):1921-31.

87. Ratte HT. Bioaccumulation and toxicity of silver compounds: a review. Environ Toxicol Chem. 1999;18:89-108.

88. Luoma NS. Silver nanotechnologies and the environment: old problems or new challenges? Project on Emerging $\mathrm{Na}$ notechnologies [Internet]. 2008, [acesso em 05 mar. 2013]. Disponível em: http://www.nanotechproject.org/process/ assets/files/7036/nano_pen_15_final.pdf.

89. Lee KJ, Nallathamby PD, Browning LM, Osgood CJ, Xu XH. In vivo imaging of transport and biocompatibility of single silver nanoparticles in early development of zebrafish embryos. ACS Nano. 2007;1(2):133-43.

90. Fabrega J, Renshaw JC, Lead JR. Interactions of silver nanoparticles with Pseudomonas putida biofilms. Environ Sci Technol. 2009; 43(23):9004-9.
91. Xu XH, Brownlow WJ, Kyriacou SV, Wan Q, Viola JJ. Real-time probing of membrane transport in living microbial cells using single nanoparticle optics and living cell imaging. Biochemistry. 2004;43(32):10400-13.

92. Scown TM, Santos EM, Johnston BD, Gaiser B, Baalousha M, Mitov S, Lead JR, Stone V, Fernandes TF, Jepson M, van Aerle R, Tyler CR. Effects of aqueous exposure to silver nanoparticles of different sizes in rainbow trout. Toxicol Sci. 2010;115(2):521-34.

93. Gao J, Youn S, Hovsepyan A, Llaneza VL, Wang Y, Bitton G, Bonzongo JC. Dispersion and toxicity of selected manufactured nanomaterials in natural river water samples: effects of water chemical composition. Environ Sci Technol. 2009;43(9):3322-8.

94. Kvitek L, Vanickova M, Panacek A, Soukupova J, Dittrich M, Valentova E, Prucek R, Bancirova M, Milde D, Zboril R. Initial study on the toxicity of silver nanoparticles (nps) against Paramecium caudatum. J Phys Chem C. 2009;113:4296-300.

95. Ward JE, Kach DJ. Marine aggregates facilitate ingestion of nanoparticles by suspension-feeding bivalves. Mar Environ Res. 2009; 68(3):137-42.

96. Reinsch BC, Levard C, Li Z, Ma R, Wise A, Gregory KB, Brown GE Jr, Lowry GV. Sulfidation of silver nanoparticles decreases Escherichia coli growth inhibition. Environ Sci Technol. 2012;46(13):6992-7000.

97. Hwang ET, Lee JH, Chae YJ, Kim YS, Kim BC, Sang BI, Gu $M B$. Analysis of the toxic mode of action of silver nanoparticles using stress-specific bioluminescent bacteria. Small. 2008;4(6):746-50.

98. Marambio-Jones C, Hoek EMV. A review of the antibacterial effects of silver nanomaterials and potential implications for human health and the environment. J Nanopart Res. 2010;12:1531-51.

99. Bottero J-Y, Auffan M, Rose J, Mouneyrac C, Botta C, Labille J, Masion A, Thill A, Chaneac C. Manufactured metal and metal-oxide nanoparticles: Properties and perturbing mechanisms of their biological activity in ecosystems. C R Geosci. 2011;343(2-3):168-76.

100. Gunawan C, Teoh WY, Marquis CP, Lifia J, Amal R. Reversible Antimicrobial Photoswitching in Nanosilver. Small. 2009,5(3):341-4.

101. Bianchini A, Wood CM. Does sulfide or water hardness protect against chronic silver toxicity in Daphnia magna? A critical assessment of the acute-to-chronic toxicity ratio for silver. Ecotoxicol Environ Saf. 2008;71(1):32-40.

102. Miao AJ, Schwehr KA, Xu C, Zhang SJ, Luo Z, Quigg A, Santschi $\mathrm{PH}$. The algal toxicity of silver engineered nanoparticles and detoxification by exopolymeric substances. Environ Pollut. 2009;157(11):3034-41.

103. Griffitt RJ, Luo J, Gao J, Bonzongo JC, Barber DS. Effects of particle composition and species on toxicity of metallic nanomaterials in aquatic organisms. Environ Toxicol Chem. 2008;27(9):1972-8. 
104. Roh JY, Sim SJ, Yi J, Park K, Chung KH, Ryu DY, Choi J. Ecotoxicity of silver nanoparticles on the soil nematode Caeno-rhabditis elegans using functional ecotoxicogenomics. Environ Sci Technol. 2009;43(10):3933-40.

105. Griffitt RJ, Hyndman K, Denslow ND, Barber DS. Comparison of molecular and histological changes in zebrafish gills exposed to metallic nanoparticles. Toxicol Sci. 2009;107(2):404-15.

106. Bilberg K, Malte H, Wang T, Baatrup E. Silver nanoparticles and silver nitrate cause respiratory stress in Eurasian perch (Perca fluviatilis). Aquat Toxicol. 2010;96(2):159-65.

107. Yeo MK, Yoon JW. Comparison of the effects of nano-silver antibacterial coatings and silver ions on zebrafish embryogenesis. Mol Cell Toxicol. 2009;5:23-31.

108. Cedervall T, Lynch I, Lindman S, Berggård T, Thulin E, Nilsson $\mathrm{H}$, Dawson KA, Linse S. Understanding the nanoparticle-protein corona using methods to quantify exchange rates and affinities of proteins for nanoparticles. Proc Natl Acad Sci U S A. 2007;104(7):2050-5.

109. Völker C, Boedicker C, Daubenthaler J, Oetken M, Oehlmann J. Comparative toxicity assessment of nanosilver on three Daphnia species in acute, chronic and multi-generation experiments. PLoS One. 2013;8(10):e75026.

110. Lee KJ, Nallathamby PD, Browning LM, Osgood CJ, Xu XH. In vivo imaging of transport and biocompatibility of single silver nanoparticles in early development of zebrafish embryos. ACS Nano. 2007;1(2):133-43.

111. Farkas J, Christian P, Gallego-Urrea JA, Roos N, Hassellöv M, Tollefsen KE, Thomas KV. Uptake and effects of manufactured silver nanoparticles in rainbow trout (Oncorhynchus mykiss) gill cells. Aquat Toxicol. 2011;101(1):117-25.

112. Massachusetts Institute of Technology, EHS Office - Potential Risks of Nanomaterials and How to Safely Handle
Materials of Uncertain Toxicity [Internet]. Massachusetts: MIT; 2010. [acesso em 10 jul. 2013]. Disponível em:

113. http://ehs.mit.edu/site/content/nanomaterials-toxicity

114. Food and Drug Administration (US). FDA continues dialogue on 'nano' regulation [internet]. 2012. [acesso em 23 jul. 2013]. Disponível em: http://www.fda.gov/downloads/ForConsumers/ConsumerUpdates/UCM258691.pdf

115. Lux Research. The nanotech report. 5. ed. New York: Lux; 2007.

116. Stensberg MC, Wei QS, MCLamore ES, Porterfield DM, Wei A, Sepúlveda MS. Toxicological studies on silver nanoparticles: challenges and opportunities in assessment, monitoring and imaging. Nanomedicine (Lond). 2011;6(5):87998.

117. Brasil, Código de Defesa do Consumidor. Lei n. 8.078, de 11 de setembro de 1990. Dispõe sobre a proteção do consumidor e dá outras providências. Diário Oficial da União. 12 set. 1990 .

118. National Institute for Occupational Safety and Health (US). Strategic Plan for NIOSH Nanotechnology Research and Guidance [Internet]. NIOSH; 2009. [acesso em 24 jul. 2013]. Disponível em: http://www.cdc.gov/niosh/ docs/2010-105/pdfs/2010-105.pdf.

119. Environmental Protection Agency (US). Control of nanoscale materials under the toxic substances control act [Internet]. 2011. [acesso em 13 jun. 2013]. Disponível em: http://www.epa.gov/opptintr/nano/\#nanomaterials.

120. Schierow L. The Toxic Substances Control Act (TSCA): implementation and new challenges. CRS Report [internet]. 2007 [acesso em 23 jun. 2013]. RL34118. Disponível em: http://www.acs.org/content/dam/acsorg/policy/ acsonthehill/briefings/tscareform/crs-tsca-implementation-2008.pdf.

Data de recebimento: 06/08/2013

Data de aceite: $27 / 11 / 2013$ 